\title{
Severe Pelvic Organ Prolapse with Large Vaginal Mucosal Defect Underwent Laparoscopic Shull's Uterosacral Ligament Colpo-Suspension and TVM Operation by Two Stage Surgery
}

\author{
Yasuyuki Kinjo', Kazuaki Yoshimura1 ${ }^{*}$, Hitomi Nakagawa1', Kazuaki Nishimura1, Toru Hachisuga² \\ ${ }^{1}$ Department of Obstetrics and Gynecology, Wakamatsu Hospital of University of Occupational and Environmental Health, \\ Kitakyushu, Japan \\ ${ }^{2}$ Department of Obstetrics and Gynecology, University of Occupational and Environmental Health, Kitakyushu, Japan \\ Email: *yoppy@med.uoeh-u.ac.jp
}

How to cite this paper: Kinjo, Y., Yoshimura, K., Nakagawa, H., Nishimura, K. and Hachisuga, T. (2017) Severe Pelvic Organ Prolapse with Large Vaginal Mucosal Defect Underwent Laparoscopic Shull's Uterosacral Ligament Colpo-Suspension and TVM Operation by Two Stage Surgery. Open Journal of Obstetrics and Gynecology, 7, 395-399.

https://doi.org/10.4236/ojog.2017.74041

Received: January 24, 2017

Accepted: April 10, 2017

Published: April 13, 2017

Copyright @ 2017 by authors and Scientific Research Publishing Inc. This work is licensed under the Creative Commons Attribution International License (CC BY 4.0).

http://creativecommons.org/licenses/by/4.0/

\begin{abstract}
A 75-year-old woman complained of anuria and a sense of discomfort with severe pelvic organ prolapse (POP). We planned tension-free vaginal mesh (TVM) surgery after curing mucosal defects and completing treatment for diabetes mellitus. Anuria and pyelonephritis relapsed repeatedly due to the failure of ring pessary therapy. Surgical treatment was required emergently. We performed a total laparoscopic hysterectomy and uterosacral ligament colpo-suspension (Shull's method). Although the vaginal apex was supported to a good position, cystocele occurred six months after the initial surgery. A TVM procedure for recurrent cystocele was performed after curing the mucosal defects, and after the improvement of glycemic control. Transvaginal native tissue repair has the advantages of low risk of ureter injury, firm colpo-suspension, and no need for mesh usage. On the other hand, it is not good at treating cystocele. Transvaginal native tissue repair should prove to be a useful surgical option for apical support without mesh.
\end{abstract}

\section{Keywords}

Pelvic Organ Prolapse, Intravaginal Mucosal Defect, Laparoscopic Native Tissue Repair, Transvaginal Mesh Surgery

\section{Introduction}

Regarding the surgical procedures for pelvic organ prolapse (POP), it is impor- 
tant to diagnose and repair the injured sites of the pelvic floor. The POP patients complained of varied symptoms individually. Patients' ages, severity, lifestyles, occupations, and hobbies must all be considered when deciding the most appropriate treatment. In the $21^{\text {st }}$ century, transvaginal mesh (tension-free vaginal mesh: TVM) operation, which was a new surgical technique, was developed in France and standardized skills are now available in many countries. But the US Food and Drug Administration (FDA) announced that surgical mesh devices had complications such as mesh exposure, pain, dyspareunia and infection, stressing the importance of adequate procedure selection [1]. For the POP patients with vaginal mucosal defects, operations should be performed after curing the defects by ring pessary therapy and administration of estrogen/progesterone. In this case, we experienced a severe POP patient who underwent a laparoscopic non-mesh surgery as an initial operation and a TVM operation for the recurrent cystocele.

\section{Case Report}

A 75year-old single-parous Japanese woman came to our hospital complaining of a sense of vaginal descent, with a high fever and anuria. She had stage IV POP with large vaginal mucosal defects (Figure 1) and cystitis due to anuria without hydronephrosis. She had untreated overt diabetes mellitus (DM). Ring pessary therapy and estrogen/progesterone administration were used to cure the anuria and the vaginal mucosal defects. A TVM operation was scheduled after the cure of mucosal defects and DM control. Anuria and pyeronephritis relapsed because the ring pessary slipped out repeatedly. She was admitted for antibiotic therapy and a bladder catheter. She couldn't get the cure of mucosal defects and DM control, so we performed a total laparoscopic hysterectomy (TLH), bilateral salpingo-oophorectomy (BSO), and vaginal apex suspension by using uterosacral ligaments under general anesthesia emergently instead of an elective TVM operation ten days after the emergency admission. Surgical procedures were described in our video paper [2]. At the beginning of the operation, after opening the retroperitoneal space, bilateral uterosacral ligaments were separated from the ureters. In addition, the inferior hypogastric nerve and pelvic nerve plexus were also separated from the uterosacral ligament. After the TLH, three ipsilateral sutures of were placed between the uterosacral ligament and the vaginal cuff according to Shull's procedure [3]. Delayed-absorbable monofilament strings \#0 MAXON $^{\circledR}$ (Covidien, Dublin, Ireland) were passed from the anterior to posterior vaginal wall, then handled to take the full thickness of the uterosacral ligament. Two additional sutures were placed distal (on the sacral side) to the initial suture. Since the uterosacral ligament and the ureter were fully-separated, it was unlikely to cause the ureter injuries. During the retroperitonization with continuous suture of absorbable string \#0 Vicryl ${ }^{\circledR}$ (Ethicon, Somerville, NJ, USA), the Douglas pouch was closed in order to prevent enterocele. After the fixation of the uterosacral ligament, $5 \mathrm{ml}$ of indigo carmine was intravenously injected and cystoscopy was performed to assess ureteral patency and potential bladder in- 
jury. The postoperative examination revealed that the vaginal apex was wellsupported without cystocele. However, cystocele occurred six months after the initial operation even though the vaginal apex was still well-supported. A TVM operation was performed for recurrent cystocele, and there was no recurrence or complication(s) for three years after the second operation. A written Informed consent was obtained from the patient for publication of this case report.

\section{Discussion}

An important conviction of POP surgery is "site specific repair", which means to diagnose the injured parts accurately and to focus repair of only those parts. De Lancy et al. reported the role of individual structures involved in vaginal support [4]. The vagina was divided into three parts, i.e., 1) the upper third is suspended from pelvic wall by upper paracolpium and cardinal ligament (level I suspension), 2) the middle third paracolpium attaches vaginal wall laterally to the arcus tendinous and fascia of the levatorani muscles and pelvic wall (level II attachment), and 3) lower third fuses with perineal membrane, levatorani muscle, and perineal body (level III fusion). In our hospital, vaginal hysterectomies and colpo-suspensions are used for level I injuries. Transvaginal mesh procedures and tension-free vaginal tape procedures/perineoplasties are used for level II and III prolapse, respectively. In the present case, a TLH, a BSO, and a uterosacral ligamentcolpo-suspension were performed for the following reasons: 1) emergent therapy was needed due to anuria and pyeronephritis after the failure of the ring pessary therapy, 2) we wanted to avoid mesh surgery because of untreated type 2 $\mathrm{DM}, 3$ ) it was difficult to perform a TVM procedure due to the large vaginal mucosal defects. Shull et al. reported that uterosacral ligament colposuspension is a reliable transvaginal native tissue repair method [3]. The three sutures were placed between the vaginal cuff and each uterosacral ligament (Figure 2). It was reported that the vaginal approach of this procedure was more difficult and risky for ureter injury [5] [6]. However, under direct visualization, laparoscopic uterosacral ligament suspension can prevent urinary tract injury; in Lin's review, 133 cases of laparoscopic vaginal vault suspension using uterosacral ligaments had no ureter injury [7].

In this case, cystocele occurred six months after post-operation, although the vaginal apex was well-supported. This clinical history presents two important issues. Firstly, this method of uterosacral ligament suspension presented the efficiency for elevating the vaginal apex (level I support) and the deficiency for prophylaxis of cystocele (level II support). Although sutures of delayed-absorbable monofilament strings were used in this case, this may be a more fragile approach than permanent sutures. Chung et al. described use of permanent sutures in uterosacral ligament suspension. It was associated with a lower failure rate than delayed absorbable sutures. In their paper, the part of all recurrent cases was anterior and apical prolapse [8]. Secondly, TVM operations are good at supporting level II. However, in this severe POP case which has the contraindications such as large vaginal mucosal defects and untreated DM, native tissue repair without mesh was a suitable procedure. 


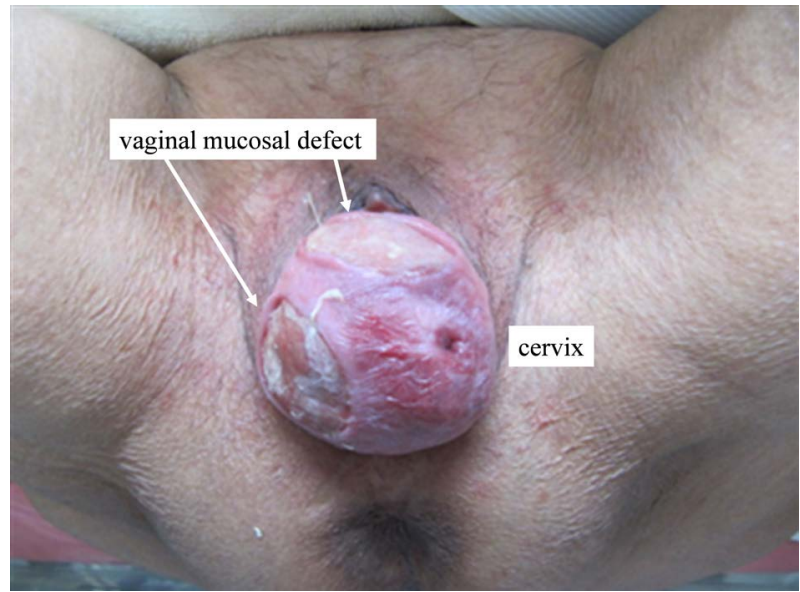

(a)

\begin{tabular}{|l|l|l|}
\hline Aa:3 & Ba:5 & C: 5 \\
\hline gh:4 & pb:3 & tvl:5 \\
\hline Ap:3 & Bp:5 & D: $\mathbf{5}$ \\
\hline
\end{tabular}

(b)

Figure 1. (a) Stage IV POP with large vaginal mucosal defect (first examination), (b) the POP-Q system.

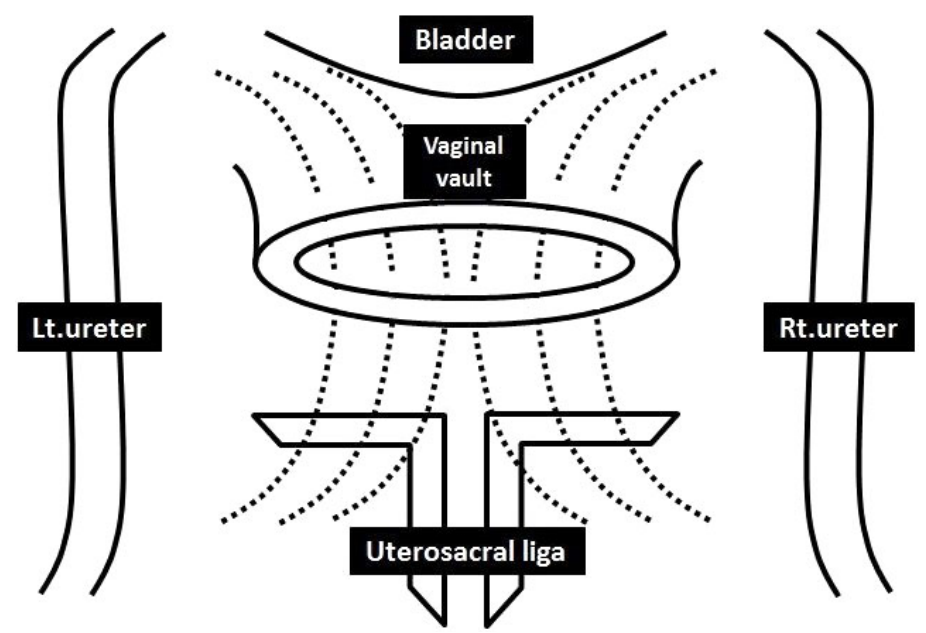

(a)

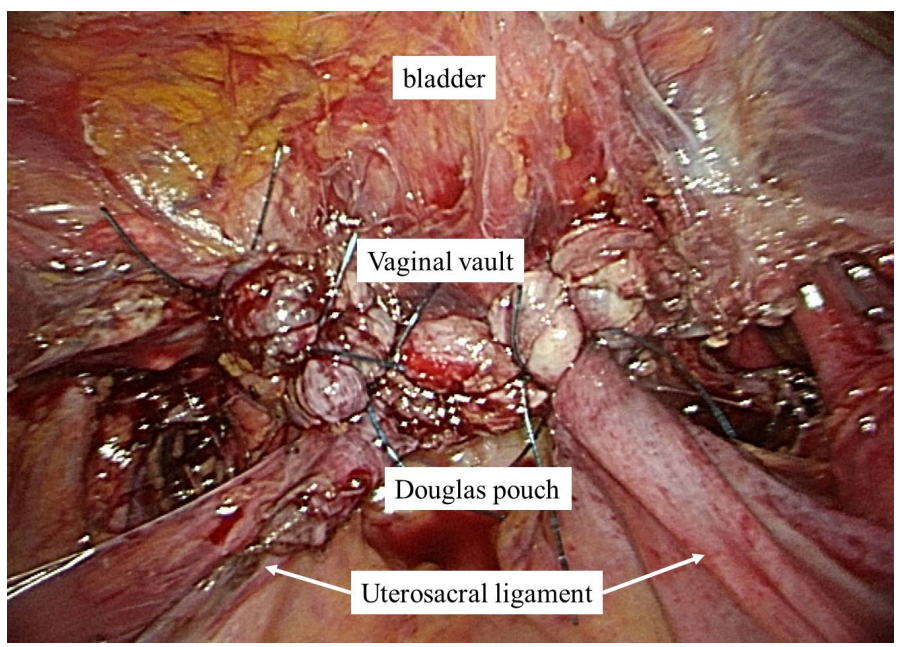

(b)

Figure 2. (a) Three ipsilateral sutures (delayed-absorbable monofilament string) placed between uterosacral ligament and vaginal cuff, (b) laparoscopic findings after colpo-suspension. 
Each patient deserves the best individualized treatment. To this end, seeking and developing new procedures is paramount. We therefore present this laparoscopic uterosacral ligament colpo-suspension (a variation of Shull's method) as an efficient new procedure for apex support.

\section{Conflicts of Interest}

The authors have no conflicts of interest relevant to this article.

\section{References}

[1] Administration, U.S.F.A.D. (2011) Urogynecologic Surgical Mesh: Update on the Safety and Effectiveness of Transvaginal Placement for Pelvic Organ Prolapse. http://www.fda.gov/downloads/medicaldevices/safety/alertsandnotices/ucm 262760. pdf

[2] Nishimura, K., Yoshimura, K., Hoshino, K. and Hachisuga, T. (2017) Laparoscopic Fixation of the Vaginal Cuff to the Uterosacral Ligaments at the Time of Hysterectomy. International Urogynecology Journal, 28, 321-323. https://doi.org/10.1007/s00192-016-3137-y

[3] Shull, B.L., Bachofen, C., Coates, K.W. and Kuehl, T.J. (2000) A Transvaginal Approach to Repair of Apical and Other Associated Sites of Pelvic Organ Prolapse with Uterosacral Ligaments. American Journal of Obstetrics and Gynecology, 183, 1365 1373.

[4] DeLancey, J.O. (1992) Anatomic Aspects of Vaginal Eversion after Hysterectomy. American Journal of Obstetrics and Gynecology, 166, 1717-1724.

[5] Vakili, B., Chesson, R.R., Kyle, B.L., Shobeiri, S.A., Echols, K.T., Gist, R., Zheng, Y.T. and Nolan, T.E. (2005) The Incidence of Urinary Tract Injury during Hysterectomy: A Prospective Analysis Based on Universal Cystoscopy. American Journal of Obstetrics and Gynecology, 192, 1599-1604.

https://doi.org/10.1016/j.ajog.2004.11.016

[6] Gustilo-Ashby, A.M., Jelovsek, J.E., Barber, M.D., Yoo, E.H., Paraiso, M.F. and Walters, M.D. (2006) The Incidence of Ureteral Obstruction and the Value of Intraoperative Cystoscopy during Vaginal Surgery for Pelvic Organ Prolapse. American Journal of Obstetrics and Gynecology, 194, 1478-1485. https://doi.org/10.1016/j.ajog.2006.01.064

[7] Lin, L.L., Phelps, J.Y. and Liu, C.Y. (2005) Laparoscopic Vaginal Vault Suspension Using Uterosacral Ligaments: A Review of 133 Cases. Journal of Minimally Invasive Gynecology, 12, 216-220. https://doi.org/10.1016/j.jmig.2005.03.014

[8] Chung, C.P., Miskimins, R., Kuehl, T.J., Yandell, P.M. and Shull, B.L. (2012) Permanent Suture Used in Uterosacral Ligament Suspension Offers Better Anatomical Support than Delayed Absorbable Suture. International Urogynecology Journal, 23, 223-227. https://doi.org/10.1007/s00192-011-1556-3 
Submit or recommend next manuscript to SCIRP and we will provide best service for you:

Accepting pre-submission inquiries through Email, Facebook, LinkedIn, Twitter, etc. A wide selection of journals (inclusive of 9 subjects, more than 200 journals)

Providing 24-hour high-quality service

User-friendly online submission system

Fair and swift peer-review system

Efficient typesetting and proofreading procedure

Display of the result of downloads and visits, as well as the number of cited articles Maximum dissemination of your research work

Submit your manuscript at: http://papersubmission.scirp.org/

Or contact ojog@scirp.org 